\title{
DESIGN STUDY OF A COLLABORATION LABORATORY FOR PRODUCT DESIGN AND DEVELOPMENT
}

\author{
Alexander DOMIAN, Robin BÄRTLE, Marc NUTZMANN and Thorsten SAUER \\ DHBW Baden-Wuerttemberg Cooperative State University, Friedrichshafen, Germany
}

\begin{abstract}
In this student research paper, a concept of a collaboration laboratory for product design and development is setup. New digital technologies (e.g., VR glasses, augmented reality, 3D scanners and printers ...) are highlighted and integrated in the concept. The paper discusses how digital technologies can significantly facilitate the collaboration of decentralised project teams. Furthermore, it also displays how small businesses, in particular, can benefit from such a facility in times of digitisation and international cooperation. Company surveys are used to find out how far such technologies already play a role in the development environment or will play in the future. It also addresses the relevance of the described technologies to international project teams. In addition, the survey provides information about the requirements and equipment of such a laboratory as desired by the companies. After an analysis of the results of the survey, a concept for the spatial design, as well as the technical equipment of a collaboration laboratory at the DHBW Ravensburg at Campus Friedrichshafen is being developed. By creating a first business model, the concept and financing of the laboratory is completed.
\end{abstract}

Keywords: Collaboration laboratory, industrial requirement study, business model for a co lab

\section{INTRODUCTION}

Cooperation and joint goal-oriented work is a central element, since we are social beings. This is also relevant in companies: With rising complexity in product development, the necessity of working in teams, often in interdisciplinary and decentralised teams, can only ensure the company's long-term success. Especially in product development creative collaboration is essential. In times of digitisation, the introduction of novel technologies such as computers and the internet have created completely new communication possibilities, which have drastically changed the way we work. Today, decentralised teams can communicate and work through various media. Nevertheless, working with new digital technologies presents opportunities but also risks regarding the quality of information transmission and therefore the development result. The potential of integrating digital collaboration in product development will be determined in this paper. The development of a concept for a collaboration laboratory at the DHBW will form the basis of an experimental laboratory for the testing of the mentioned technologies, collaboration possibilities, research to increase and facilitate collaboration efficiency. Businesses and education institutions can take great benefit from testing technologies that they do not have in their own environment and review them for potential use. In addition, a survey is conducted to find out which technologies companies are already using today and to determine their needs for a collaboration laboratory [1].

\section{DIGITAL COLLABORATION - STATE OF THE ART}

Definitions and explanations of the relevance of this topic are given below. Furthermore, examples of present technologies outline possible equipment for a collaboration laboratory.

\subsection{Collaboration in general: Purpose and definition}

Collaboration is an interaction process of joint interworking. Subordinated, communication builds the basis of this process in the way of information exchange. Coordination is on second and mid-level, which can be described as the coordination of activities. E-collaboration systems are considered a hypernym for systems that support all three levels of the interaction process by using suitable media 
and technology. Especially in product development, collaboration is very important, e.g. to share interdisciplinary knowledge, find solutions, minimise iterations, shorten time to market. The cooperation is mostly done with the intention to pursue common goals (Figure 1).

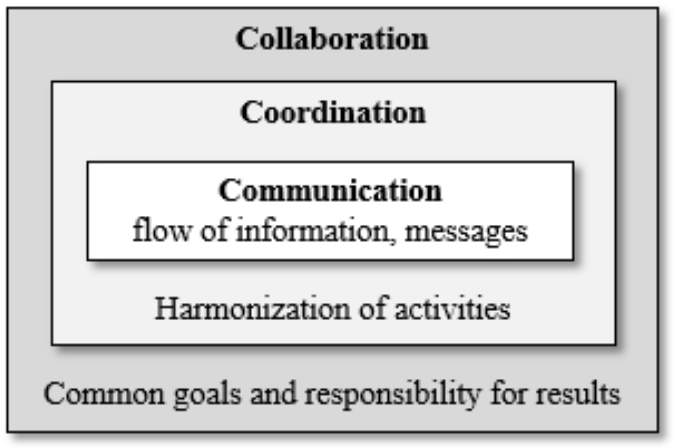

Figure 1. Model of the interaction process in teams [2]

E-collaboration systems support collaboration in product development mainly through joint creation and editing of electronic documents. Of great relevance is also the risk of immense costs for troubleshooting in advanced stages of the product creation process, which can be significantly reduced by a solid, collaborative and interdisciplinary development. "The Rule of Ten" describes that at each stage of product development, a product flaw means ten times more cost, figure 2.

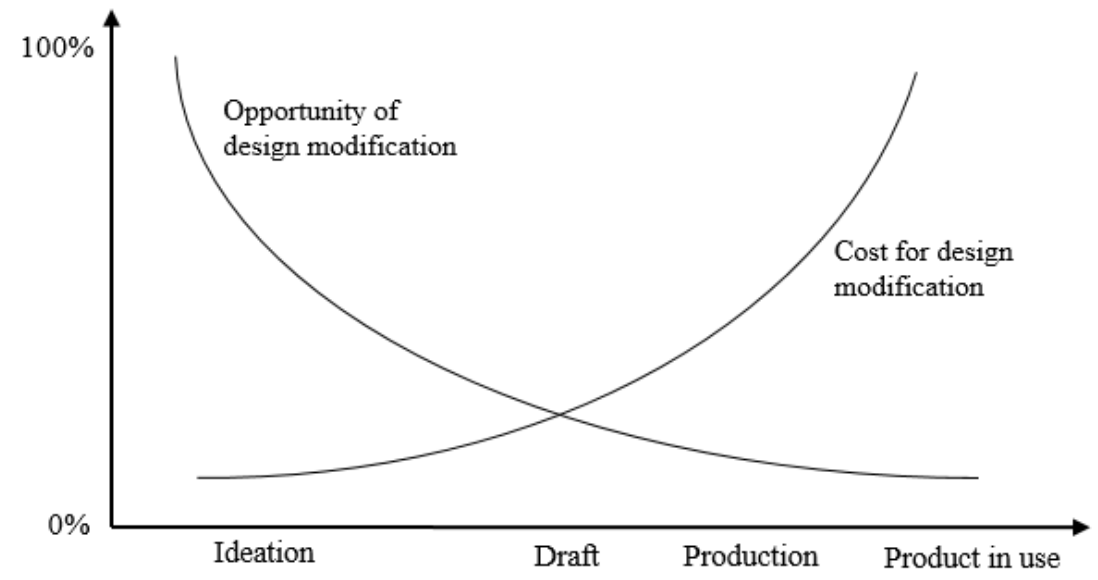

Figure 2. Relation of product creation phases and cost for modification acc. [3]

Modifications in early stages of product development are possible at low cost, whereas modifications at advanced stages results in high cost. This shows the importance of decent collaboration in conception and development phase. Moreover, studies show that $60 \%$ to $70 \%$ of the products costs are defined in the early stages of engineering design and development. [6] [7]. All specifications need to be clarified before the start of production. The use of digital collaboration technologies helps to improve the exchange of information in decentralised teams, e.g. local specifications. Moreover, teams in different time zones are supported to work on one digital model, a digital twin or prototype and direct exchange in expertise.

\subsection{Supporting devices}

Collaboration in development teams can be improved by a variety of devices. The use of a simple electronic whiteboard already helps to make sketches simultaneously. Furthermore, documents can be created synchronously as well as asynchronously using a wide range of management tools. Simultaneous (synchronous) multi-person processing can be realised by so-called application-sharing functions, which for example allow the control of a remote computer or system.

Technologies that can primarily support product development activities are mainly additive manufacturing (3D printing), VR and AR techniques, or 3D scanning for reverse engineering. With VR and AR, virtual prototypes of the product can already be created and integrated into the rest of the environment in the early stages of product development. The 3D scan enables the return of physical 
geometries to digital CAD data. 3D printers allow worldwide-distributed teams to share a physical printed prototype by exchanging the CAD files and help discussions on product improvement.

\subsection{Examples of state of the art use cases}

Mixed Reality, VR and AR applications are already used in product development and production. One of the biggest advantages of using these technologies is the visualisation of products and drawings as well as prototypes with a minimum effort-risk ratio.

- An example is the in Dublin, Ireland based company Linde AG. They enable a virtual inspection of already planned industrial plants. This is made possible only by the use of VR glasses [4].

- Deutsche Bahn (German Railways) has also introduced its programme EVE (Engaging Virtual Education), which allows employees to train to operate a train at their deployment sites in a virtual train. Natural movements and gestures are detected by appropriate sensors and transformed into the virtual environment.

- Research institutes such as the Fraunhofer-Institute for Degeneration Mechatronics (IEM) are also researching on integration and use of AR data glasses in the production environment. Through a mock-up (flexible workplace prototype), procedures and actions can be tested first, before a rigid implementation in reality takes place [5].

\section{DESIGN OF A COLLABORATION LABORATORY}

In order to be able to test the use and networking of the various technologies in the collaboration of development teams, it requires a laboratory in which the use can be experienced and carried out under real conditions. In such a laboratory, different technologies can be compared in a uniform environment. Their benefits in terms of improving collaboration, such as the flow of information, can also be determined empirically.

\subsection{Survey - Collaboration in product development today}

In order to determine the current state of the use of technologies for collaboration in product development, a survey was setup. In addition to insights about the current situation, improvement potentials in the collaboration should be determined. The results of the survey provide insights to market relevance and market acceptance of using state-of-the-art technologies to support product design and development collaboration.

\subsubsection{Subject of the survey}

The survey consists of 11 questions. One part of the survey is aimed specifically at the current situation in the environment of the respondent or company. The other part refers more to general experience in using modern technologies to support team collaboration. Improvement wishes and needs as well as questions on previous reasons for the avoidance of such technologies have also been included. Future needs are to be derived from the results on the current potential for improvement.

\subsubsection{Results of the survey}

The survey was sent out to selected companies in the engineering and chemistry industry, especially in the Baden-Wuerttemberg region, which is known for its high density of well-known international companies. The area around Lake Constance is one of the top five innovation areas of the country. An indicator therefore is the top rank in Germany for assigned patents [8] [9]. The success of the selected companies is mostly due to innovative technologies and strong product development efforts.

In order to obtain a high expertise, corresponding development engineers of the companies were directly addressed and asked to participate in the survey. Most of the contacts to established companies were made by fellow students and lecturers of the DHBW. In general, the DHBW partner companies like to support research projects, which is why the ratio of completed surveys is quite high. Twenty-seven companies with a size of at least 250 employees have been contacted so far. Of these, seventeen (63\%) have taken part in the survey. Below, the final results of the survey are shown.

About $95 \%$ of respondents work at different locations with other teams in their organisation. This relates to the need of cooperation within the company (e.g. with subsidiaries) as well as with external partners (suppliers and customers). Various technical means are used to implement cooperation in decentralised teams. Primarily, systems for the exchange of information in the form of text, images and sound are used. Not surprisingly, all respondents quoted their use of e-mail and telephone 
(conference calls) for this purpose. Only half of the respondents already use central file servers to manage documents. With the exception of only one respondent, the use of virtual reality or augmented reality technologies for knowledge transfer has not been widely used so far. Nevertheless, there are coordination problems triggered by excessive amount of e-mails or complex processes, especially due to the use of such technological means. According to the respondents, these are mainly caused by differences in knowledge or competence between the various team members.

Additionally, $50 \%$ of all respondents expressed optimisation potential when working together in decentralised teams. Only $20 \%$ are satisfied. A very high quantity of one-third of the respondents did not express any positive or negative experiences.

Particularly with regard to the product development, the effort in different phases of the product development was examined, too. Here, especially at the beginning of a project, the coordination of the specifications show an increased effort. The integration of external project partners in the process was also assessed with increased effort in contrast to the remaining phases of the project.

Nevertheless, the majority of respondents stated that they have not yet used integrated system approaches such as simultaneous engineering, simulation methods or virtual environments in product development to share information across departments. On the other hand, $70 \%$ of all respondents are familiar with virtual project rooms and environments.

The main reasons why digital technologies have so far failed to appeal to respondents are the lack of skills and the additional work generated by the use of such technologies. The lack of a comprehensive approach to the integration of digital technologies is also criticised. Only a few participants stated that they could not imagine any application or that the price/performance ratio is too unprofitable. The following chart shows the various reasons for the previous rejection of the use of digital technologies.

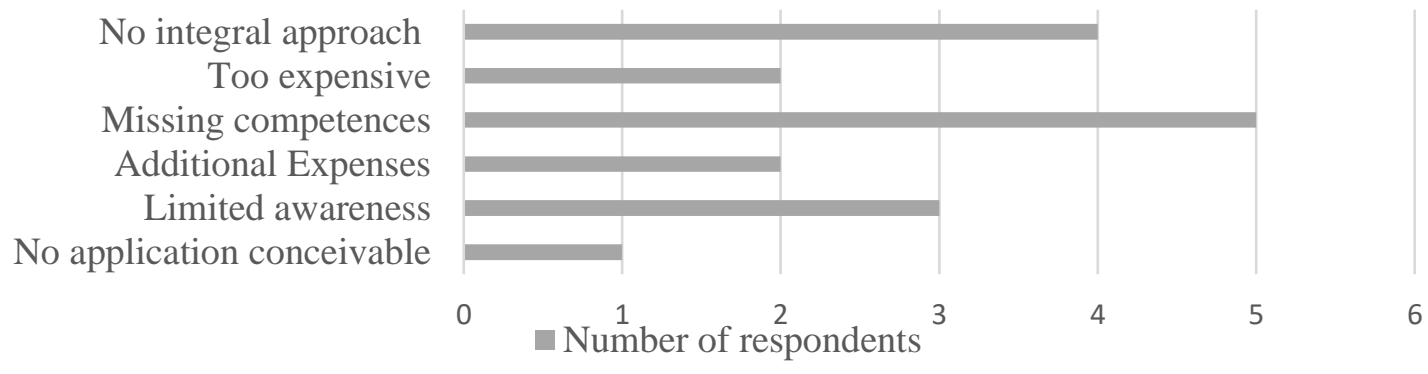

Figure 3. Reasons for rejection of the use of digital technologies

As a possible field of use, a large part of the respondents (about 75\%) cite the elaboration of a development project with design, simulations and test runs. Nevertheless, two thirds of all respondents can also imagine an application in early concept phases, e.g. for brainstorming, prototyping.

The survey shows a clear picture. Although the technologies have hardly been used so far, many respondents are familiar with them. The interviewees see possible applications. The main reasons why no application and full integration has taken place so far are additional effort and a lack of knowledge. The lack of integration of technologies into existing systems is also a major critical point.

\subsubsection{Conclusions of the survey}

All participants of the survey have shown great interest in the topic of the survey. The desire of the majority of respondents to improve their own working conditions shows that the offer of such technologies for product development can generate benefit. Digital technologies can be used especially in the project phases of project definition and creation of the specifications as well as in the design phase (CAD, FEM, testing).

The establishment of a laboratory for collaboration in product development can demonstrate this benefit by illustrating the application of techniques using practical examples. This step can refute previous reasons for rejecting digital technologies. The laboratory can thus demonstrate the need for system solutions for digital technologies in product development.

\subsection{Derivation of a Concept}

Regarding the requirements for the collaboration laboratory, some categories were already worked out in previous research work [11], [12]. These relate e.g. on mobility, spatial design, handling, 
accessibility as well as interfaces of the laboratory. The key results were that the laboratory should take up as little space as possible, because space is a valuable asset in companies and institutions. In addition, the handling of provided technologies should be intuitive, so users do not need additional trainings.

In addition to the results of the survey, it is important to align the requirements with current trends in product development in order to ensure the acceptance of the laboratory for potential partners. In the field of product development, current digitisation technologies, such as Augmented Reality, Internet of Things, Product Life Cycle Management and the outsourcing of software systems to the cloud are present solutions nowadays. New processes such as additive manufacturing can significantly reduce prototyping iterations and time. The digital twin of a product allows engineers and customers to experience a virtual product, therefore ensures greater efficiency and better usability. These technologies should be an integral part of the collaboration laboratory.

\subsubsection{Requirements on laboratory equipment}

According to the survey, new work principles and methods, as described below, have come up over the last years in the field of product development. These working methods are already part of several lectures at universities in the field of mechanical engineering and design. The best way to learn about these methods and technologies is to use the application itself, which confirms the educational purpose of this laboratory.

- Reverse Engineering: If the geometry of the hardware of a product does not exist in digital form, then methods and devices are used to represent a digital data model of the product. As a result, further processing can take place within the virtual process chain. Such technologies are mainly used after manual modifications, for comparison with the target data of the CAD geometry or for the preparation of hand-moulded parts. The digitisation is usually done in several steps, first the raw data are obtained by means of a non-contact 3D measuring method. These are processed and processed in a CAD programme. [10] To enable the use of this technology in the laboratory, a 3D scanner, a powerful computer and a CAD programme is needed.

- Rapid Prototyping: Rapid prototyping refers to manufacturing processes for the rapid production of prototypes. The production of these prototypes is usually done directly from the data of the CAD model. This eliminates devices, tools, and other manufacturing equipment. For the operation of the laboratory, 3D printers are suitable for the creation of prototypes. This also requires a computer with appropriate software. Of particular importance, here is the integration with the systems of reverse engineering, so that without additional effort e.g. a copy of a geometric object can be created. To improve the surface, cleaning or post curing of the component, additional equipment may be needed.

- Visualisation of work results: Any 3D data such as CAD, FEM or reverse engineering can be visualised. In addition to the 3D data, other documents such as drawings are discussed or agreed together. The collaboration laboratory requires additional equipment such as projectors, screens or VR technology for 3D visualisation.

\subsubsection{Use case "collaboration laboratory"}

With the realisation of such a collaboration, small and medium-sized companies in particular will have the opportunity to test the future vision of collaboration in product development and to recognise the potential for improving collaboration. In addition, an actual real-life example from their company can be tested based on the available technologies: Partners can bring in actual projects and work on them in the lab. Furthermore, the collaboration laboratory may enhance the quality of education in the field of mechanical engineering and design significantly. Especially by student projects, for example design studies and research projects with universities from different locations, modern collaboration methods can be applied, tested optimised concerning efficiency and system integration.

\subsection{Business Model}

With the introduction of such a laboratory, a high level of investment is required for the equipment. An average six-figure amount cannot be funded alone by an educational institution such as the DHBW. For this reason, the establishment of a business model to cover the costs is essential. After completion of the survey, interested companies should be asked for financial support. A pay-per-use 
concept is considered with a starting fee that authorises interested parties to use the lab. By this, the covering of running cost can be ensured.

\section{SUMMARIES}

Collaboration will become one of the most important methods of work in companies in the future. Projects and workflows need to be coordinated, especially in decentralised teams. The most important factors are transparency, interdisciplinary information exchange and the enabling of spontaneous communication. Therefore, teaching the application of digital technologies and work methods, as described in this paper, will help students to adapt to the rapid changes in product development. Furthermore, partner companies can take great benefit from the collaboration laboratory.

Within the scope of this work, the survey has already provided insights into the use of digital technologies for collaboration in product development. The relevance of well-executed collaboration of decentralised teams a major factor, which justifies the benefit of such a laboratory. With the later design of an actual concept for the laboratory, the implementation at the DHBW will take place after ensuring financial aspects. The procedure described here for developing a concept of such a laboratory may be applied at comparable educational institutions, e.g. over the nine DHBW sites in BadenWuerttemberg, but also at partner companies. Assessment of collaboration and finally improvement of such will be a future field of research for students and research fellows. Possible research fields are e.g. an assessment approach for collaboration, improvement and optimisation of collaboration (team setup, technologies, usage of lab), setup of learning concepts.

\section{REFERENCES}

[1] Schellhammer S. Riemer K. and Meinert M. Collaboration in the Digital Age. How Technology Enables Individuals, Teams and Businesses. Springer International Publishing. 2019

[2] Riemer K. and Strahringer S. HMD Praxis der Wirtschaftsinformatik. (Practice in Business Informatics). eCollaboratio. dpunkt. 2009.

[3] N.N. Wirtschaftlichkeitsbewertung VR - Nutzen, Kosten, Modelle, Indikatoren. Whitepaper. (Whitepaper on evaluation of the cost-effectiveness of VR. Advantages, costs, models, indicators). Virtual Dimension Center (VDC). Fellbach. 2011

[4] Reder B. VR und AR fassen im Business Fuß. (VR and AR break into business). com! Professional, 7/2018. Ebner Media Group GmbH \& Co. KG. München. https://www.commagazin.de/d1/9/6/6/2/7/7/VR-AR.pdf [Accessed on 2018, December 21], 2018.

[5] N.N. VR und AR in der Produktentwicklung und Produktion. (VR and AR in product development and production). www.studio-b12.de; STUDIO B12. Braunschweig. https://studiob12.de/content/projects/vrar/virtual-reality/pdf/7-VR_und_AR_in_der_Produktentwicklung_ und_Produktion.pdf [Accessed on 2019, January 10], 2017.

[6] Bullinger H.-J. and Voegele A. Wirtschaftliche Grundbegriffe für den Konstrukteur. (Business Management Basics for Design Engineers). VDI (Hrsg.): Konstrukteure senken Herstellkosten: Methoden und Hilfen. VDI-Berichte Nr. 457. VDI Verlag. Düsseldorf. 1982.

[7] Schultz V. Basiswissen Controlling. (Basics in Controlling). ISBN: 978-3-423-50907-7. dtv (Deutscher Taschenbuch Verlag GmbH \& Co KG). München. 2010.

[8] N.N. Innovationindex 2018 für die Kreise und Regionen in Baden-Württemberg. Pressemitteilung 290/2018. Statistisches Landesamt Baden-Württemberg. Stuttgart. 2018.

[9] Asche, S. Schaffe, Schaffe Patente anmelden. (Make, make, register patents). VDI nachrichten, 10/ 2019. VDI Verlag, Düsseldorf. 2019.

[10] Breutner E., Neukircher H. and Maas G. Virtuelle Produktentwicklung (Virtual Product Development). Vogel Business Media, Wuerzburg 2013.

[11] Nutzmann M. KoLabBW. Baden-Wuerttemberg Collaborative Laboratory. Submitted proposal for a research project to the Baden-Wuerttemberg State Ministry of Science, Research and the Arts, 2018.

[12] Madlener M. and Sohm K. Konzeptentwicklung eines Kollaborationslabors für die Produktentwicklung. (Conception of a collaboration laboratory for product design and development.) Study project. DHBW Ravensburg - Baden-Wuerttemberg Cooperative State University Ravensburg, Campus Friedrichshafen. 16.07.2018 